It is hardly to be expected that an entirely new classification such as that proposed will at once be universally adopted, but it is believed that as time goes on it will recommend itself more and more to petrographers as a quantitative system of classification, much more precise and definite than any that has been hitherto proposed, and having the further advantage of being based on thoroughly scientific principles and capable of indefinite expansion, if necessary, to meet the growing needs of the science. Frank D. Adams.

McGill University, Montreal.

Ueber das Hirngewicht des Menschen. By F. Marchand. Abh. d. math.-phys. Classe d. Königl. Sächsischen Ges. d. Wissensch., Bd. XXVII., 1902, No. IV., pp. 393-482.

Professor Marchand, of Marburg, has accumulated the largest number of human brain-weights ever published, and in a large series of tables, containing 1,169 cases, he gives a thorough analysis of these data. Marchand discusses the influences affecting the weight of the brain, such as the cause of death, bodily stature, sex and age. He finds a notable increase in the brain-weight of persons dying of diphtheria and other acute diseases, owing, no doubt, to the hyperæmia and cedema of this organ. In new-born children the average weight is 380 grams for males and 353 grams for females. Combining with these the infants less than one week old, the averages are 371 grams for males and 361 grams for females. These weights are doubled by the end of the first year, and tripled at the end of the third. After the fifth year the increase in the weight of the brain is more gradual. The figures show that in most persons the maximum brain-weight is attained at about the twentieth year in males, the average being about 1,400 grams, and at about the seventeenth year in females, the average being 1,275 grams. The reduction of the average brain-weight due to senile atrophy occurs in the eighth decade in men and in the seventh decade in women. The maximum absolute weight in Marchand's series was 1,705 grams in a male. Many high brain-weights were omitted from the tabulations on account of hydrocephalus, brain-tumor, meningitis and other brain affections. Low brain-weights, less than 1,200 grams in males and less than 1,100 grams in females, constituted about five and seven per cent., respectively, of all the cases, usually in phthisical subjects or in those dying of wasting diseases. The tables show a certain relation existing between the stature and brain-weight, but the ratio of increase is a very inconstant one. Finally Marchand discusses the relation of the sexes as to their brain-weight, and concludes that the lesser weight of the brain in women is not alone dependent upon her smaller stature, for a comparison of both sexes of the same stature shows the male brain to be invariably the heavier. In the growing child, until a stature of seventy centimeters is attained, the brain-weight increases proportionately to the increase in body-length, irrespective of age or sex; thereafter, however, the male brain begins to outstrip that of the female. Woman's lesser brain-weight, like her lesser head-circumference, as compared with males of the same stature, seems to be an expression of the different organization of the female body.

E. A. S.

\section{SCIENTIFIC JOURNALS AND ARTICLES.}

The Popular Science Monthly for February has for frontispiece a portrait of Carroll D. Wright, president of the American Association. Asaph Hall has an article on 'The Science of Astronomy,' in which attention is called to the influence of science in promoting harmony among nations. Bradley M. Davis discusses 'The Evolution of Sex in Plants,' as illustrated by the Algæ. Alverton W. Price shows 'The Economic Importance of Forestry,' and Frederick A. Woods gives the seventh of his papers on 'Mental and Moral Heredity in Royalty,' this one dealing with the house of Nassau and Brunswick. An account of 'The Smithsonian Institution' is reprinted from its last report. Roger Mitchell discusses 'Jewish Immigration,' showing that it presents a somewhat serious problem in New York. Wesley Mills treats of 'The Behavior of Blind Animals,' adducing instances to show how great 